\title{
Marine integrons containing novel integrase genes, attachment sites, attl, and associated gene cassettes in polluted sediments from Suez and Tokyo Bays
}

\author{
Hosam Elsaied $^{1,2}$, Hatch W Stokes ${ }^{3}$, Keiko Kitamura ${ }^{1}$, Yasurou Kurusu ${ }^{4}$, Yoichi Kamagata ${ }^{1}$ \\ and Akihiko Maruyama ${ }^{1}$ \\ ${ }^{1}$ Microbial and Genetic Resources Research Group, Bioproduction Research Institute, National Institute of \\ Advanced Industrial Science and Technology, Higashi Tsukuba, Ibaraki, Japan; ${ }^{2}$ Department of Genetics, \\ National Institute of Oceanography, Cairo, Egypt; ${ }^{3}$ Institute for the Biotechnology of Infectious Diseases, \\ University of Technology, Sydney, New South Wales, Australia and ${ }^{4}$ Department of Molecular Microbiology, \\ College of Agriculture, Ibaraki University, Ami, Ibaraki, Japan
}

\begin{abstract}
In order to understand the structure and biological significance of integrons and associated gene cassettes in marine polluted sediments, metagenomic DNAs were extracted from sites at Suez and Tokyo Bays. PCR amplicons containing new integrase genes, intl, linked with novel gene cassettes, were recovered and had sizes from 1.8 to $2.5 \mathrm{~kb}$. This approach uncovered, for the first time, the structure and diversity of both marine integron attachment site, attl, and the first gene cassette, the most efficiently expressed integron-associated gene cassette. The recovered 13 and 20 intl phylotypes, from Suez and Tokyo Bay samples, respectively, showed a highly divergence, suggesting a difference in integron composition between the sampling sites. Some intl phylotypes showed similarity with that from Geobacter metallireducens, belonging to Deltaproteobacteria, the dominant class in both sampling sites, as determined by 16S rRNA gene analysis. Thirty distinct families of putative attl site, as determined by the presence of an att-like simple site, were recovered. A total of 146 and 68 gene cassettes represented Suez and Tokyo Bay unsaturated cassette pools, respectively. Gene cassettes, including a first cassette, from both sampling sites encoded two novel families of glyoxalase/bleomycin antibiotic-resistance protein. Gene cassettes from Suez Bay encoded proteins similar to haloacid dehalogenases, protein disulfide isomerases and death-oncuring and plasmid maintenance system killer proteins. First gene cassettes from Tokyo Bay encoded a xenobiotic-degrading protein, cardiolipin synthetase, esterase and WD40-like $\beta$ propeller protein. Many of the first gene cassettes encoded proteins with no ascribable function but some of them were duplicated and possessed signal functional sites, suggesting efficient adaptive functions to their bacterial sources. Thus, each sampling site had a specific profile of integrons and cassette types consistent with the hypothesis that the environment shapes the genome.
\end{abstract}

The ISME Journal (2011) 5, 1162-1177; doi:10.1038/ismej.2010.208; published online 20 January 2011

Subject Category: integrated genomics and post-genomics approaches in microbial ecology

Keywords: integrons; gene cassettes; metagenome; polluted marine sediment

\section{Introduction}

Integrons are DNA elements first described in multidrug-resistant pathogenic bacteria (Stokes and Hall, 1989). Their defining features (Figure 1) are an integrase gene, intI, which encodes a site-specific recombinase, IntI, and an integron-associated recognition site designated attI. This recombination system is designed to capture individual genes when such genes are part of a mobilizable genetic

Correspondence: A Maruyama, Microbial and Genetic Resources Research Group, National Institute of Advanced Industrial, Science and Technology, AIST, 1-1-1, Higashi Tsukuba, Ibaraki 305-8566, Japan.

E-mail: maruyama-aki@aist.go.jp

Received 22 June 2010; revised 14 October 2010; accepted 14 December 2010; published online 20 January 2011 element known as gene cassette (Hall et al., 1999). Insertion of a cassette into an integron occurs via an IntI-mediated site-specific recombination reaction between attI and the cassette-associated recombination site, attC (also designated a 59-base element in earlier literature) (Collis et al., 2002). Genes in cassettes normally do not include a promoter. However, where examined, integrons possess a promoter, $P_{\mathrm{c}}$, that drives the transcription of cassette genes when cassettes are inserted in an integron (Collis and Hall, 1995).

The integron recombination system is unusual in comparison to other such systems. Most notable among the differences is the fact that the attC sites recognized by the IntI protein are relatively diverse in that such sites are variable in both sequence and length when different gene cassettes are compared. 


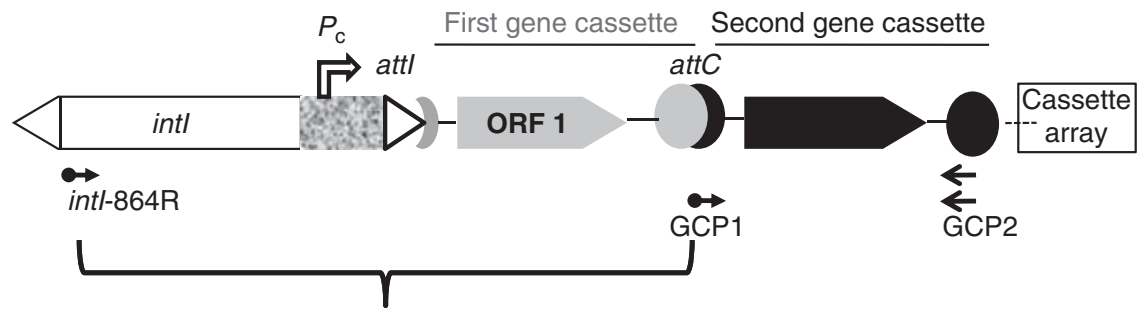

Figure 1 A generalized structure of the marine integrons, indicating intI and attC specific primer binding sites, marked by left and right arrows, and the sequence region/s missed in previous studies, marked by a brace, and uncovered in this study. intI, integrase gene; $P_{\mathrm{c}}$, gene cassette expression promoter; $a t t I$, gene cassette attachment site; attC, gene cassette base element.

They have a structural conservation, however, and this is important in IntI recognition and reaction catalysis (Stokes et al., 1997; MacDonald et al., 2006). This structural similarity includes the presence of two IntI-like simple sites and an overall structure that comprises an imperfect inverted repeat. The sequence of the attI sites within an integron class is highly conserved. However, these sites, like the associated intI genes themselves are highly divergent in DNA sequence between classes. One of the most studied attI sites is attI1, the attachment site associated with class 1 integrons (Partridge et al., 2000). This site comprises a single intI-like simple site adjacent to which are two direct repeats, which comprise IntI1binding domains. attI sites of other integron classes possess a simple site but the presence of adjacent direct repeats is more variable (Nield et al., 2001).

Integrons are phylogenetically diverse elements and are dispersed among a wide range of both pathogenic and environmental bacteria (Mazel, 2006; Boucher et al., 2007). At least three integron classes contribute to the spread of antibiotic resistance (Partridge et al., 2009). Outside the antibioticresistance domain, the biological significance of environmental integrons was demonstrated in their flexibility to acquire and express adaptive genes for several environmental stresses (Elsaied et al., 2007; Robinson et al., 2007; Koenig et al., 2009; Elsaied and Maruyama, 2010). This unique integron feature creates a system that provides for an enormous pool of adaptive genes to be mobilized, rearranged and disseminated among environmental bacteria. Indeed, the reservoir of adaptive genes capable of being mobilized by integrons has as yet no known upper limit but must, at the very least, number in the thousands. As a result, integrons have a key role in the evolution of bacterial adaptive genome and can greatly influence bacterial diversity and adaptation in ways that other DNA mechanisms cannot (Holmes et al., 2003).

Marine integron/gene cassette metagenomes have been studied based on random PCR amplifications of the intI gene, and of gene cassettes in separate techniques, using primers specific for each target (Elsaied et al., 2007; Koenig et al., 2008; Wright et al., 2008; Rodríguez-Minguela et al., 2009). These molecular approaches lacked the ability to show the linkage between intI and gene cassettes in a single amplicon. In some cases, this made it difficult to identify integron-associated gene cassettes unambiguously. Moreover, these studies did not recognize the structure and diversity of marine integron attI site and integron-associated first gene cassette. The gene cassette recombination site attC has been studied in marine integrons from the views of both structure and recombination activity (Elsaied et al., 2007). Consequently, the sequence structure and diversity of attI are needed to complete our understanding about the mechanism of integration of marine integron-associated gene cassettes. The first gene cassette, which is located adjacent to the attI site of an integron (Figure 1), is the last one integrated and, consequently, involves in the last adaptation response to changing conditions. As it is the closest gene to the promoter, $P_{\mathrm{c}}$, its expression level is the highest among other integron-associated gene cassettes (Collis and Hall, 1995). Thus, this gene cassette is a good target to find new strongly expressed adaptive genes in metagenomes (Huang et al., 2009).

This study had two aims. The first one was filling of the gap in the structure of the marine integrons by production of PCR amplicons, which contained integron sequences that previously not uncovered, such as $P_{\mathrm{c}}$, attI and the gene cassettes most closely linked to attI. The second was demonstrating the functional diversity of marine integrons in capturing gene cassettes, especially the first gene cassette, capable of adaptation and sustaining of bacteria in marine sediments polluted with varieties of industrial wastes. These goals were achieved in metagenomic DNAs extracted from two sampling distant sites, at Suez Bay and Tokyo Bay; with different pollutant characteristics that may enable in understanding the hypothesis that integrons have the potential to capture genes important in bacterial niche adaptation. We combined both statistical and phylogenetic analyses to estimate the bacterial communities, based on the 16S rRNA gene and composition of intI in the sampling sites.

\section{Materials and methods}

Sampling

Grab samples of surface sediments were collected at water depths of about $20 \mathrm{~m}$ from two Bay sites, 
where the pollution stresses were expected to stimulate spreading and diversity of integron/gene cassette metagenome (Koenig et al., 2009). The first site, El-Zeitia, is located at the north terminus of Suez Bay and constitutes the south gate of Suez Canal, Egypt, $29^{\circ} 57.160^{\prime} \mathrm{N}, 32^{\circ} 31.725^{\prime}$ E. El-Zeitia is the most contaminated site of Suez Bay. It is exposed daily to high loads of petroleum wastes coming from the petroleum refining industry around the site, crude oil spills from the fixed oil pipes under the water and ships traveling through the Suez canal as well as other various anthropogenic wastes from the surrounding urban region (El-Agroudy et al., 2006; Nemr et al., 2006; this study) (Supplementary Table 1). The second site is located at the center of Tokyo Bay, $35^{\circ} 26.71^{\prime} \mathrm{N}, 139^{\circ}$ $50.18^{\prime} \mathrm{E}$, where the sediment is contaminated with a mixture of industrial domestic wastes such as chlorinated polycyclic aromatic hydrocarbons such as dioxin and perfluorinated compounds (Naito and Murata, 2007; Uchimiya et al., 2007; Horii et al., 2009; Zushi et al., 2010) (Supplementary Table 1). The sediment samples were treated with $100 \mathrm{mM}$ EDTA buffer and kept at $-80^{\circ} \mathrm{C}$ for further analyses.

Metagenomic DNA extraction and molecular analyses Bulk microbial DNAs were extracted from $50 \mathrm{~g}$ of sediment, $10 \mathrm{~g}$ per each extraction, at each sampling site using PowerMax Soil DNA Isolation Kit (Catalog no. 12988-10, Mo Bio Laboratories, Carlsbad, CA, USA) according to the manufacture's protocol with modifications. A combination of mechanical force using beads, heat and chemical detergents was applied to lyse microbial sediment cells. The released crude lysates were bound to silica spin filters to purify metagenomic DNAs. The sizes of the extracted DNAs were checked by electrophoresis on a $0.9 \%$ agarose gel against a LambdaHindIII digest marker (New England BioLabs, Hitchin, Hertfordshire, UK) with ethidium bromide staining.

To generate PCR amplicons, containing intI, the gene cassette promoter, $P_{\mathrm{c}}$, the integron attachment site, attI, and integrated gene cassettes, the primer intI-864R, specific for binding to the sequence encodes the conserved amino acids RHS(T)FATHLL, IntI box II, was used coupling with the primer GCP2, designed from a conserved region of gene cassette base element, attC, (Table 1; Figure 1) (Elsaied et al., 2007). PCR reaction mixture, $50 \mu \mathrm{l}$, contained $10 \times$ LA buffer II $\left(\mathrm{Mg}^{2+}\right.$ plus), $0.2 \mu \mathrm{M}$ primer, $400 \mu \mathrm{M}$ dNTP each, 2.25 U Takara LA Taq Polymerase (Takara, Japan) and 5-30 ng DNA template. Shuttle, combined annealing-extension temperatures, long PCR amplification reaction was performed with the thermal cycler, iCycler (Bio-Rad, Richmond, CA, USA). PCR was started with an initial denaturation at $96{ }^{\circ} \mathrm{C}$ for $2 \mathrm{~min}$, followed by 30 cycles with $30 \mathrm{~s}$ at $95^{\circ} \mathrm{C}$, annealing extension at $60-62^{\circ} \mathrm{C}$ for $10 \mathrm{~min}$, with increasing of $1{ }^{\circ} \mathrm{C}$ every 10 cycles, followed by a final elongation at $72{ }^{\circ} \mathrm{C}$ for $10 \mathrm{~min}$. PCR products were checked by electrophoresis on a $1.0 \%$ agarose gel.

Another PCR approach, using the primers GCP1 and GCP2, was used to recover gene cassettes generally (that is not uniquely the first cassette) from the studied metagenomic DNAs according to the methodology described by Elsaied et al. (2007).

In order to identify the bacterial communities at the sampling sites, the primers $27 \mathrm{~F}$ and $1492 \mathrm{R}$ (Table 1) (Lane et al., 1985) were used to amplify the bacterial 16S rRNA gene from the metagenomic DNAs from which the integron amplicons were obtained.

All the PCR products had $3^{\prime}$-A overhangs to facilitate TA-cloning into TOP10 Escherichia coli using a TOPO XL PCR-cloning kit according to the manufacturer's instructions (Catalog no. K4750-20, Invitrogen Life Technologies, Carlsbad, CA, USA). Only cells containing XL-TOPO vector with the insert were competent to grow with kanamycin. Colonies of these cells were screened directly by sequencing using vector primers $\mathrm{T} 7$ and an ABI $3730 \times 1$ 96-capillary DNA analyzer (Applied Biosystems, Foster City, CA, USA).

\section{Sequence analyses}

Sequencing results were introduced to FASTA, http://fasta.ddbj.nig.ac.jp/top-e.html, to determine their similarity to known sequences deposited in DNA database. Sequences for intI and gene cassette open reading frames (ORFs) were submitted to Transeq, http://www.ebi.ac.uk/emboss/transeq/, to obtain the inferred amino-acid sequences. The correct intI ORFs were identified from the presence of diagnostic motifs. Gene cassette promoter

Table 1 Primers used in this study

\begin{tabular}{|c|c|c|c|}
\hline Primer & Sequence & Primer & Expected product size \\
\hline intI-864 $\mathrm{R}^{\mathrm{a}}$ & 5'-YAGCAGATGNGTGGCRAAVSWRTGSCG-3' & GCP2 & Varied \\
\hline $\mathrm{GCP}^{\mathrm{b}}$ & $5^{\prime}$-GCSGCTKANCTCVRRCGTTRRRY-3' & GCP2 & Varied \\
\hline GCP2 $2^{b}$ & 5'-TCSGCTKGARCGAMTTGTTRRRY-3' & & \\
\hline $27 \mathrm{~F}^{\mathrm{c}}$ & 5'-AGAGTTTGATCCTGGCTCAG-3' & $1492 \mathrm{R}$ & $\sim 1500 \mathrm{bp}$ \\
\hline $1492 R^{\mathrm{c}}$ & 5'-GGTTACCTTGTTACGACTT-3' & & \\
\hline
\end{tabular}

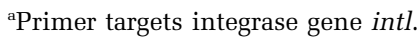

brimer targets gene cassette base element attC.

cPrimer targets 16S rRNA gene. 
sequence, $P_{\mathrm{c}}$, was identified by the promoter predictor in the software GENETYX, ver.9, http://www.sdc.co. jp/genetyx/product/genetyx9/news.html. attI sequence was identified by observing the simple gene cassette integration site, consisting of a pair of inversely oriented IntI1-binding domains, together with two further directly oriented IntI1-binding sites designated strong and weak (Partridge et al., 2000). Gene cassettes were identified as described previously (Stokes et al., 2001).

\section{Statistical analyses}

Grouping of sequences into phylotypes was done, based on genetic distances, using the Mothur software package V.1.7.2 (Schloss et al., 2009), where intI and 16S rRNA gene sequences, having 100\% deduced amino acid identities and $>97.0 \%$ nucleotide identities over the regions compared, respectively, were grouped into a single phylotype (Hartmann and Widmer, 2006; Elsaied et al., 2007). The gene cassette richness was determined based on grouping of cassettes that had $>70.0 \%$ nucleotide identities into a single cassette type (Koenig et al., 2008).

The diversities of the obtained sequences were analyzed by several methods in the Mothur software package. The LIBSHUFF analyses (Singleton et al., 2001) were used to estimate homologous and heterologous coverage of both intI and 16S rRNA gene clone libraries as a function of evolutionary distance for pairwise reciprocal comparisons (library A compared with library B and vice versa). Differences in coverage were considered significant at $P$-values of $<0.05$. Rarefaction analyses (Simberloff, 1978) were used to plot the expected number of phylotypes as a function of the number of sequences sampled. Chao 1 richness estimator and Shannon-Weiner index were applied to calculate the potential number and diversity of gene cassette types, respectively (Shannon and Weaver, 1963; Chao, 1984).

\section{Phylogenetic analyses}

The phylogenetic analyses, based on deduced amino-acid and nucleotide sequences of the intI and 16S rRNA gene phylotypes, respectively, and corresponding sequences from the databases, were performed by applying the neighbor-joining algorithm and drawing the trees using the MEGA 3.1 software (http://www.megasoftware.net/). The branching patterns of the constructed phylogenetic trees were confirmed by reconstruction of the phylogenies using two other methods of analysis, namely maximum parsimony and maximum-likelihood, contained within the Phylip package, http:// evolution.genetics.washington.edu/phylip.html.

\section{Protein prediction analyses}

First gene cassette ORF deduced proteins that had no significant homology with those in databases were introduced to online protein prediction programs InterProScan sequence search, Psortb and ProtParam, located at ExPASy proteomics server http://www.expasy.org/tools/\#secondary, in order to predict protein functional sites, cellular localization, theoretical isoelectric focusing point, pI and stability, respectively.

\section{Nomenclature and accession numbers of the recorded} sequences

All recovered sequences were from metagenomic DNAs and consequently, the source organism could not be identified. Hence, we have adopted a nomenclature whereby each clone was the descriptor of the name of the sampling site followed by the number of the clone, for example, Suez1 and so on. The gene cassette had the same site name description followed by two letters GC (Gene Cassette(s)); and two numerical codes representing the number of the clone followed by the number of the gene cassette; for example, SuezGC1.1 means the first gene cassette in Suez clone 1, while SuezGC1.2 means the second gene cassette in the same clone.

The recorded sequences were deposited in the DNA database under accession numbers from AB546978 to AB546998 and from AB547085 to AB547105 for sequences, which contained intI, $P_{\mathrm{c}}$, attI and gene cassettes, recovered from Suez and Tokyo Bay samples, respectively. The accession numbers from AB546999 to AB547084 and from AB547106 to AB547123 represented gene cassette sequences generated by the primers GCP1 and GCP2 from Suez and Tokyo Bay samples, respectively. The $16 S$ rRNA gene sequences were deposited under accession numbers from AB530169 to AB530200 and from AB530201 to AB530247 for Suez and Tokyo Bay sequences, respectively.

\section{Results and discussion}

Production of diverse PCR amplicons contained all integron structural features

From two different marine sediment metagenomes, we could amplify DNA fragments that contained intI, the gene cassette promoter $P_{\mathrm{c}}$, attI and at least the first integrated gene cassette up to the point of the binding of the primer GCP2. Amplicons had a length of up to about $2.5 \mathrm{~kb}$. Sequence analysis of 21 randomly selected clones from each clone library, containing identifiable inserts, implied that most of the clones in the current libraries contained integron-related sequences based on the presence of relevant features. The high efficiency of recovery suggests that the primers used here were more selective than those originally used by Nield et al. (2001) where a high number of false positives was observed. The integron-containing amplicons had sizes ranging from 1805 to $2180 \mathrm{bp}$ and from 1771 to $2500 \mathrm{bp}$, a feature of diverse amplicons obtained from Suez and Tokyo Bay metagenomes, 
respectively. Amplicon size differences were predominantly due to the presence of the different length and number of recovered integrated gene cassettes.

The sampling sites were dominated by Delta/ Epsilonproteobacteria and unique compositions of integrase

16S rRNA gene sequences were used to identify the bacterial communities and to provide an indication of the putative sources of integrons in the sampling sites. Sequence analyses of 50 clones from each of the 16S rRNA gene clone libraries obtained 32 and 47 phylotypes, representing the bacterial diversity in Suez and Tokyo Bay samples, respectively.

Both samples were dominated by phylotypes belonging to the Delta/Epsilon subdivision of Proteobacteria. Also, both samples contained phylotypes related to Gammaproteobacteria, Planctomycetes and unclassified bacteria. On the other hand, some phylotypes formed unique phylogenetic lineages characterizing each sampling site. The Tokyo Bay sample showed an expansion of bacterial diversity by occurrence of phylotypes belonging to bacterial phyla that were not recorded in the Suez Bay sample such as Bacteroidetes and Chlorobi. In contrast, the phyla Chloroflexi and Firmicutes were represented only in the Suez Bay sample (Figure 2a).

Analyses of 21 integron-containing sequences, from each sampling site, obtained 13 and 20 intI phylotypes from Suez and Tokyo Bay samples, respectively. The rarefaction curves for both intI and 16S rRNA gene sequences of Tokyo Bay sample showed parallel unsaturated diversities (Figures 3a and b), implying that the analyzed sequences represented a fraction of the total phylotype composition of the site. Although the 16S rRNA gene phylotypes could mostly cover the bacterial composition in the Suez sample, as shown by saturation of the rarefaction curve after only 30 clones, the intI rarefaction curve did not show saturation and further sampling of Suez intI is likely to have revealed additional diversity. Unsaturated sampling of intI has been reported in almost all previously studied marine metagenomes (Rodríguez-Minguela et al., 2009). The environments from which these samples were derived were polluted. This was most evident in the Suez Bay sample and this may lead to a limitation in microbial diversity by dominance of only few phylotypes, but with diverse integrons and gene cassettes, which are able to tolerate contamination (Berthe-Corti and Nachtkamp, 2010).
The results from LIBSHUFF analyses showed that the Suez 16S rRNA gene clone library did not differ from that of Tokyo $(P=0.06)$ (Table 2). The only explanation of this pattern was that the diversity of the Tokyo library sequences encompassed and described some sequences in the Suez library. On the other hand, Suez-intI phylotypes differed significantly from that of Tokyo, indicating the high divergence between the two intI populations. The fact that the site-specific environmental characteristics shape the structure of integrons may establish endemic intI pools (Labbate et al., 2009). This intI sequence divergence was clearly demonstrated in the distribution of most of current intI phylotypes within three unique phylogenetic clusters (Figure 2b). Tokyo-intI phylotypes forming the cluster I showed phylogenetic distinction from the phylotype Suez-intI-3. A similar phylogenetic differentiation occurred between Suez-intI phylotypes and Tokyo-intI-1 within the cluster II. The cluster III comprised only three Suez-intI phylotypes constituting unique phylogenetic lineages. On the other hand, several intI phylotypes showed phylogenetic relationships with those recovered from different environmental DNA sources such as deep-sea and soil (Figure 2b), expanding the biogeographically distribution of integrons in both marine and terrestrial environments (Elsaied et al., 2007; Rodríguez-Minguela et al., 2009). It was not possible to unambiguously identify the organisms that contained these integrons. However, the phylotype Tokyo-intI-11 showed phylogenetic relationship, by forming a monophyletic clade, with that of Geobacter metallireducens, a species represented by the current phylotypes Tokyo.16S.23 and Tokyo.16S.24, suggesting bacterial sources for integrons in Tokyo Bay sample (Figures 2a and b).

The one previous study that recovered near fulllength environmental intI sequences was very limited in scope (Nield et al., 2001) and other studies have recovered only small fragments internal to the gene $(\sim 400 \mathrm{bp})$ and without associated gene cassette contextual information (Elsaied et al., 2007; Rodríguez-Minguela et al., 2009). The current study obtained intI genes with sizes ranged from 738 to $1269 \mathrm{bp}$, and from 696 to $1269 \mathrm{bp}$; from Suez and Tokyo Bay samples, respectively, revealing near complete intI sequence structure, including the $\mathrm{N}$-terminus, and contained all IntI motifs including Patch I, box I, Patch II, Patch III and most of box II (Nunes-Duby et al., 1998).

Multiple alignments of deduced amino acids of current intI phylotypes showed a conservation in

Figure 2 Consensus trees were constructed based on 16S rRNA gene nucleotide sequences (a) and intI deduced amino-acid sequences (b). The trees showed the phylogenetic relationship between the recovered sequence phylotypes and their homologues from database. The trees were constructed by neighbor-joining analyses and confirmed by maximum-parsimony and maximum-likelihood methods. Bootstrap values of $>50 \%$ were indicated at the branch roots. Recovered sequences were highlighted in bold. Abbreviations $(\beta),(\gamma)$ and $(\delta)$ represented the classes Betaproteobacteria, Gammaproteobacteria and Deltaproteobacteria, respectively. The bars represented 0.05 and 0.2 changes per a nucleotide and an amino acid, respectively. 
a

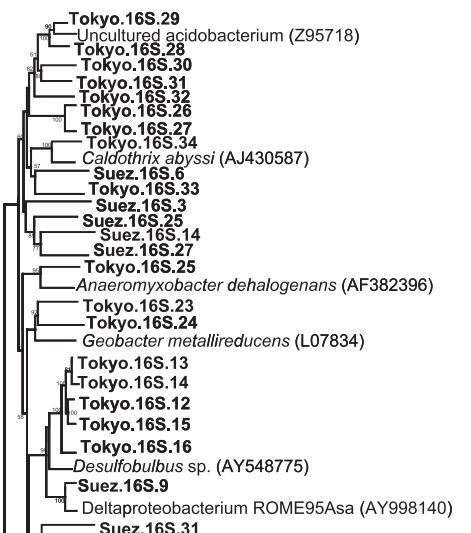
Suez.16S.3

Tokyo.16S.21

Lesulfobacterium anilini (EU020016)

Tokyo.16S.22

Suez.16S.20

Desulfobacterium vacuolatum (AF418178)

" $\left[\begin{array}{l}\text { Desulfosarcina variabilis (M34407) } \\ \text { Desulfobacterium cetonicum (AJ237603) }\end{array}\right.$

- Tuez.16S.10

Tokyo.16S.18

Fokyo.16S.1

Tokyo.16S.17

4 Deltaproteobacterial endosymbiont (AJ620511)

Sulfate-reducing

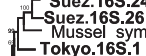

- Tokyo.16S.1

Lokyo.16S.4

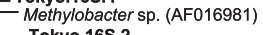

CTokyo.16S.2

Tokyo.16S.8

Pseudomonas sp. (AB013829)

Tokyo.16S.10

Tokyo.16S.11

Tokyo.16S.6

Alkalilimnicol

TTokyo.16S.9

Suez.165.2

ehrlichii (AF406554)

rinomonas sp. (EF094505)

Vibrio cholerae (EU130474)

Klebsiella pneumoniae (G0214541) Methylobacillus flagellatus (DQ287787)

- Nitrosomonas eutropha (AY123795)

Nitrosomonas eutropha (AY123795)

Dechloromo

Suez.16S.12

Suez.16S.32

Suez.16S.17

Tokyo.16S.36

Arcobacter sp. (AJ271654)

Tokyo.16S.37 Suez.16S.28

- Symbiont epsilonproteobacterium Dex60-82 (AJ431218

[Suez.16S.1

L L Suez.16S.15

Hydrothermal vent bacterium 49MY (AB091293)

Suez.16S.8

— Clostridium methylpentosum (Y18181)

Tokyo. $16 \mathrm{~S} .35$

Chlorobium

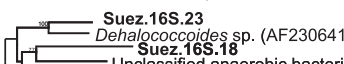

Unclassiled anaerobic bacterium dechlorinate aroclor 1260 (DQ168648)

Unclassified nitrogen-removing bacterium (AJ224539)

Suez.16S.29

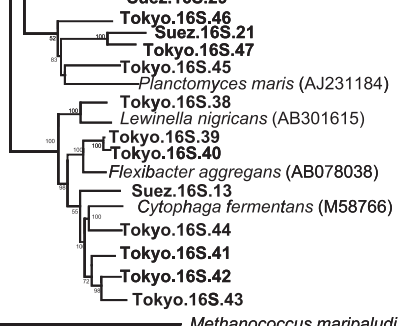

we
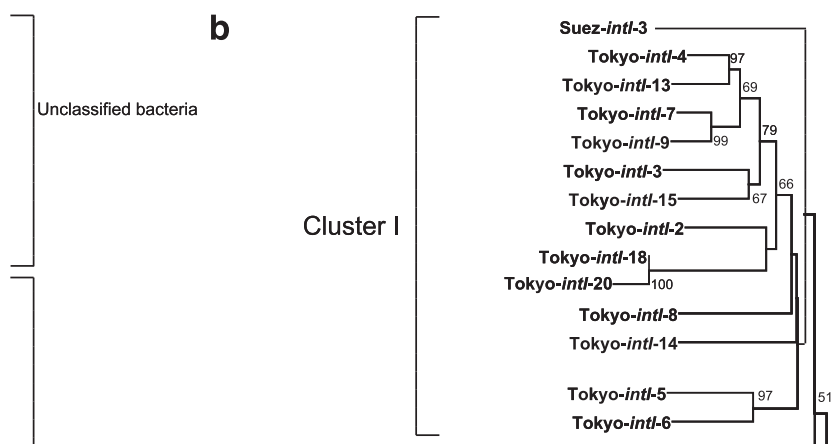

Uncultured bacterium, mine tailings (AY283626) Uncultured bacterium, 160m depth, Arctic Ocean (DQ282265)Tokyo-intl-10

Uncultured deep-sea mussel symbiont (AB273726)(Y)

Tokyo-intl-17-

Deltaproteobacteria Uncultured bacterium, rainforest soil (DQ282215)

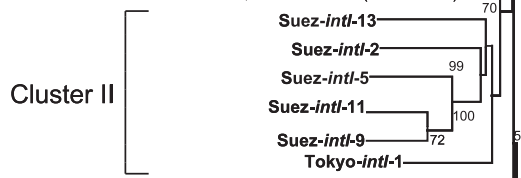

Uncultured deep-sea Calyptogena sp. symbiont (AB273727)( $(\gamma) 7^{100}$ E. coli Intl.1 (AB061794)(Y) -

K. pneumoniae Intl.3 (AY219651)(V) Alkalilimnicola ehrlichei (CP000453)(v) Geobacter metallireducens (CP000148)(8)

Tokyo-intl-19-

Methylobacillus flagellatus (CP000284)(B) Dechloromonas aromatica (CP000089)(B) Nitrosomonas eutropha (CP000450)( $(\beta)-100$

$$
\begin{aligned}
& \text { Tokyo-intl-12 } \\
& \text { Suez-intl-8 } \\
& \text { Tokyo-intl-16- }
\end{aligned}
$$

Uncultured bacterium BAL3, soil, Intl 8 (AF314189) Uncultured bacterium, agricultural soil near pig farm (FJ377605) Pseudomonas alcaligenes (AY038186)(Y) Nitrococcus mobilis (AAOF01000031)(v)

Suez-intl-1

95

Uncultured bacterium PG11, soil, Intl.7 (AF314190)

Uncultured bacterium PG2, soil, Intl 6 (AF314191)

Desulfuromonas acetoxidans (AAEW02000041)( $(8)$

Chlorobium phaeobacteroides (CP000492)(Chlorobi) Chloroherpeton thalassium (CP001100)(Bacteroidetes) Shigella sonnei Intl.2 (AY639870)(y)

Vibrio cholerae 01 biovar El tor Intl.9 (AY035340)(Y) Vibrio cholerae Intl. 4 (AF055586)(V) Vibrio mimicus Intl.5 (AF180939)(v)

Uncultured bacterium, 180m depth, Arctic Ocean (DQ282287) Pelobacter carbinolicus (CP000142)(8)

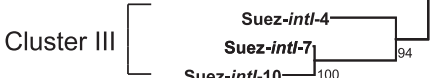

Uncultured bacterium, $1000 \mathrm{~m}$ depth, Washing

Uncultured bacterium, deep sea hydrothermal vent fluid (AB258273) Bacteriophage Lambda sp. (J02459) 
structural motifs with those from clinical and environmental isolates, but included some aminoacid mutations (Messier and Roy, 2001; Nemergut et al., 2004) (Supplementary Figure 1). Several Tokyo-intI phylotypes showed substitutions in the conserved glutamic acid, E121, patch I motif. The phylotype Tokyo-intI-20 contained four additional
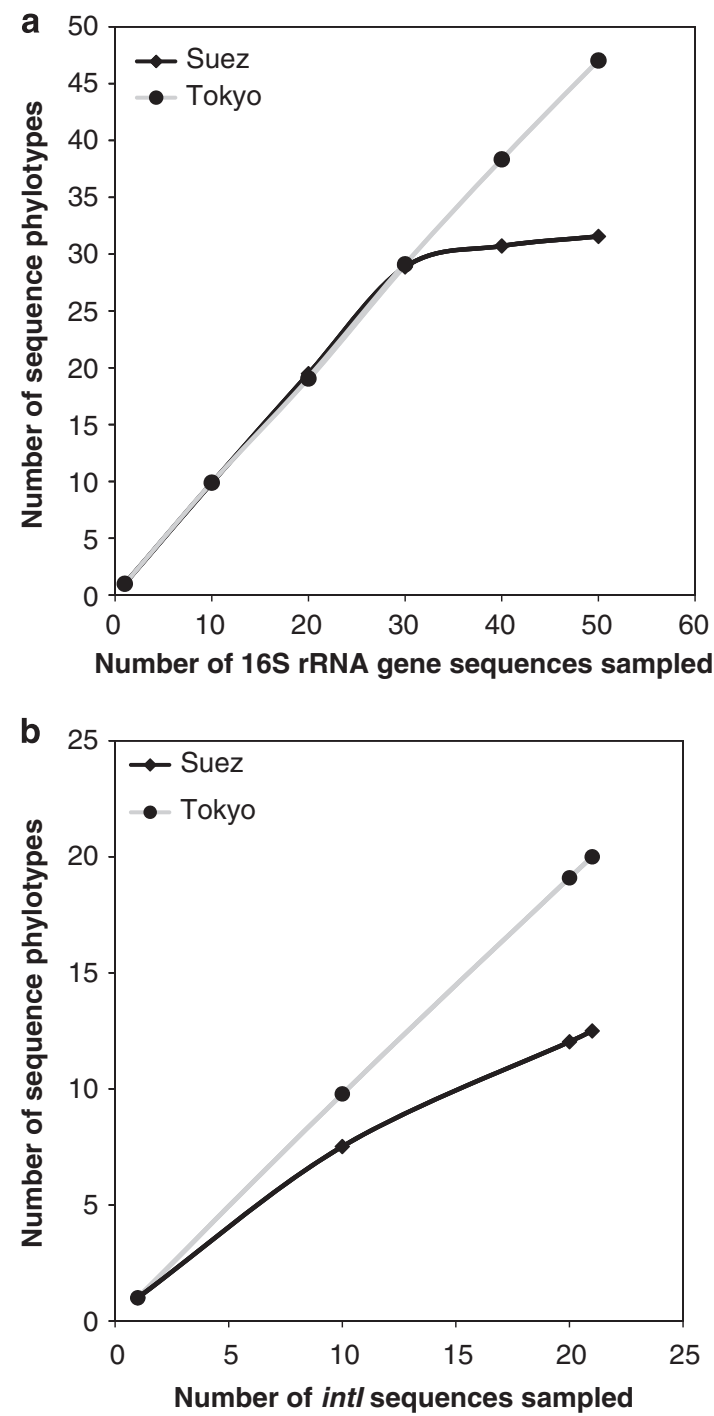

Figure 3 Rarefaction curves for the expected number of $16 \mathrm{~S}$ rRNA gene phylotypes (a) and intI phylotypes (b). amino acids in the patch II motif beside several mutations including substitutions of argenine (R) instead of the conserved lysine (K171), patch II motif; serine (S) and proline (P) instead of the conserved tryptophan (W229) and phenylalanine (F233), respectively, patch III motif; and alanine (A) instead of conserved histidine, H277, box II motif (Supplementary Figure 1). On the other hand, the phylotype Tokyo-intI-13 lacked five amino acids including the catalytic amino acid $\mathrm{H} 277$, box II motif. It was found that the substitutions in W229 and $\mathrm{H} 277$ resulted in IntI1 being completely unable to bind to the attI1 site, while substitutions in E121 and K171 did not disturb DNA-binding activity of IntI1 (Messier and Roy, 2001). The phylotype Tokyo-intI-10, the shortest current IntI sequence, 232 deduced amino acids, suffered from deletions of the motifs box I, patch II, patch III and the first four amino acids, including the catalytic H277, of box II. It was not clear whether this phylotype, Tokyoint I-10, represented an intI pseudogene that had lost the protein-coding ability and consequently, recombinase activity. Recent multigenome analyses of bacteria revealed that the proportion of integrase pseudogenes is significantly high, suggesting a different evolutionary dynamic for this class of genes (Liu et al., 2004; Nemergut et al., 2008). However, this intI sequence was located adjacent to attI and two integrated gene cassettes with an identifiable attC (acc. no. AB547094), representing an integron-associated gene cassette structure.

Recovered putative attI sites were diverse and possessed a characteristic simple site but mostly lacked IntI-like direct repeat binding sites

This study recorded 30 diverse families of attI-like sequences from the studied marine integrons (Figure 4). Multiple alignments with attI1 and those recorded previously in environmental samples showed the existence of the putative attI integration simple site, the essential region for attI recombination activity, in all recovered sequences (Figure 4). Moreover, the locations of the putative attI sites relative to the linked intI gene were consistent with known integrons (Partridge et al., 2000). The simple site contained known IntI1-binding domains in the clones Suez20, Tokyo5, 9, 10 and 14 (Figure 4).

While possessing an identifiable simple site, most of the recovered attI sites in this study lacked

Table 2 LIBSHUFF coverage for integrase and 16S rRNA gene clone libraries

\begin{tabular}{|c|c|c|c|c|c|c|}
\hline Gene & Clone library & Analyzed clones & Phylotypes & $\operatorname{Cov}_{\text {hom }}(\%)$ & $\operatorname{Cov}_{\text {het }}(\%)$ & $\mathrm{P}$ \\
\hline \multirow[t]{2}{*}{ Integrase intl } & Suez & 21 & 13 & 84.0 & 60.0 & 0.001 \\
\hline & Tokyo & 21 & 20 & 70.0 & 47.0 & 0.007 \\
\hline \multirow[t]{2}{*}{ 16S rRNA gene } & Suez & 50 & 32 & 56.0 & 55.0 & 0.060 \\
\hline & Tokyo & 50 & 47 & 65.0 & 52.0 & 0.001 \\
\hline
\end{tabular}

Homologous $\left(\mathrm{Cov}_{\text {hom }}\right)$ and heterologous $\left(\operatorname{Cov}_{\text {het }}\right)$ coverage percentages of libraries were given. Probability values $(P)$ for the significance of differences between homologous and heterologous coverage in reciprocal comparisons as a function of evolutionary distance were also given. 


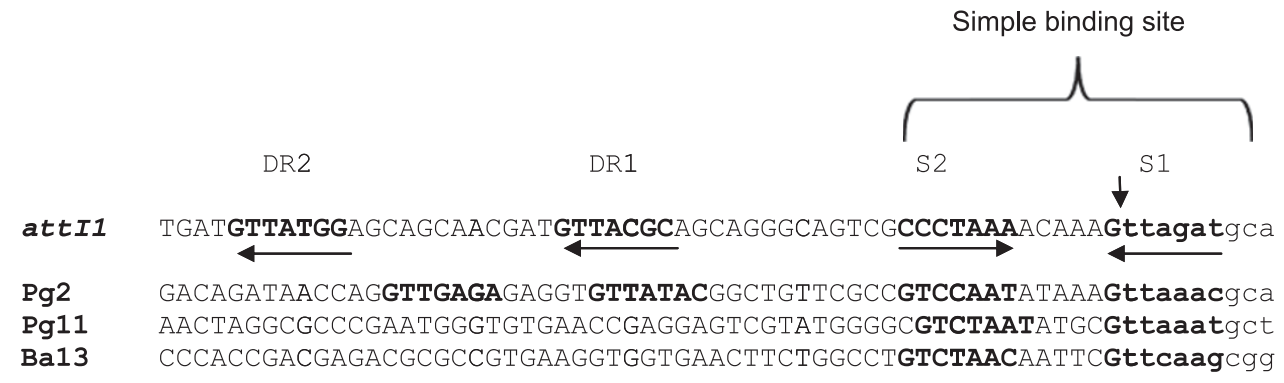

Suez4 GCGAAATATAGTTCACTATGTTACGCAGCTAAAAGTATTAACAAACTAATACACTGttagacagc (2)

Tokyo17 TCTCGTTAACAGAGAAGCTTCCTATCTCGTTAGCAGAGAAGCTGTAGAATAAACTGttaggcCC

suez1 AATCTTATTAACTAATAGCATAATATTTTACGTCTAATAGGACGTCTAGTATTATGttcggcaaa (2)

Suez2 TGGATTAGGCAGATTCTGCCTAATACCTGAAAATACAGATTCTGTCTAAGTCACTGttagccgca

Suez5 CCCGAAAAAGCCGCCAATATCAACTTATCAGGGCAAATTGCCCTGATAATAAATTGttagctgtt (2)

Suez 6 ACACTTACACGGCATCCACATAACACCCTAAAAAACGGGCTCCGTAGATATCACTGttaggcgaa

Suez 7 GGATACGCGACAGAATAGCGGCAGGGATATCGGACACATGTGGGGTATAGTCCTAGttagattgC

Suez8 AGGAATTTTTCCTGAACTACCAATTATCAGGGAGAATTGACCTGATTATAAATGGttaagcaca

Suez12 AGGAATTTTTCCTGAATTACCAATTATCAGGGAAAATTGACCTGATAATAAATGGttatgctca

Suez13 AGGAATTTTTCCTGAACTACCAATTATCAGGGAAAATTGACCTGATTATAAATGGttaagcaca (4)

Suez 9 TATTATATCCCCCAAATGTCCGATTGTAAAAAGAACATTGGGGGTTCTAATTCTAGttatgtgta

Suez10 CGACTTATATCGAGTCGGTATAACTCCGTAAATTACCGAGTCGGTATATATCACTGttagtcagt (2)

Suez15 GATTTTTATTTCAATGAGGTCCGTGCTCTGTATTGCAGAGAGTTTTGAGATTTGttctgtcag

suez20 CAAATTATGGAATTTTTCTGTCTATCCCAAATTGTTTTTTCTGTCTAATACACTGttaggcgca

Tokyo1 TGGATTAGGTCGACACTACCTATTACCGTAAATTGTTGTTTCGATCTATATCACTGttatgtgta

Tokyo2 ACGGACAACACGGCTTGGGCTGCGGACTATATCACCCCACACCGCATAATATGCTGttagacgac

Tokyo3 AgATAGGAGTTGCAAGAAATGTGCTATAAGGAACAGGCTGATAATGGAATAGGTTGttcaacggg

Tokyo7 AGATATGAGTTGCAAGAAATGTGCTATAAGGAACAGGCTGATAATGGAATAGGTTGttcaacggg

Tokyo4 CATGAGATAGAATTGCAAGGAACATGCTAGAAAAGGGCTGATACGgGAATAGATGgttgcgtact

Tokyo5 GGACTATATCGCGTGAGCATCGAACATAGAACACATAGTAACTACCCAATACGCTGttaggcaga

Tokyo6 CACTAATCTGCGAGTCTATGTTTATTTACTAATGGTAGTCTCAGCCTAATACGCTGttagctgtc

Tokyo8 TTGAATAAAAGCGCATAGCACAATATCTGTTAAAAGAGAGTCAACCCAATATGCTGttagcggga

Tokyo9 TAGGAATAGATTGCATAGGCTGATATTAATATCAGCCCGTTCAATCTAATATGCTGttaggttga

Tokyo10 ACGGGCTATAAGGTGACTGTATTTAACTTCCTATATGGCAGTCGTTCAATAAGCTGttagattgC

Tokyo11 GTGTGCTCTGTCTAGTATTTTATCACACTTACTGGGTGGTCCCCATTCAATAATAGttagccagC

Tokyo12 TTGATATCGCCACAAAATGCGGCAACAATATGAGACGGAATCTACTTACTCTACTGttaggcgtc (2)

Tokyo13 CGGGATAAAGATTGTCGACGTGATAATGCTATTGTGTCGTACAGTCTAATATGCTGttatgctga

Tokyo14 AACCCAAAGGTTGCTACAATGCTACTTATGTCAATCCGTAACAACCTAATACAATGttagacaac

Tokyo16 AAAACATAGCCTAAAAGTCGTAAGACAATACTGACTTTTAGGCCACCTAATTGTTGttatgcggc

Tokyo18 TAGAATATAATGTTAGCAGGACTGATATTTATGTAGTGCGGAATGAATTATTGAAGttgaccoag

Tokyo20 CGTAATTATCAGAAATGTCGCAAAACAAATACGACATTTGGGTCCTCCAATTTAAGttaggggct

Tokyo21 TCGAACTATTACGCTCGGGCTCTACGCAATATCAGCCCGCGCAGTAGAATATAATGttaggtgCa

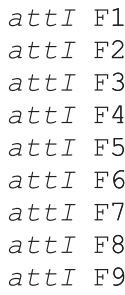

att I F10

att I F11

attI F12

attI F13

attI F14

attI F15

att I F16

attI F17

attI F18

att I F19

attI F20

attI F21

attI F22

att I F23

attI F24

attI F25

attI F26

attI F27

attI F28

att I F29

attI F30

Figure 4 Multiple alignments of recorded putative attI families (attI F1-F30), which were oriented according to attI1 length (65 bp) (Partridge et al., 2000) and attI sequences, Pg2, Pg11 and Ba13 (Nield et al., 2001). The 7-bp integrase binding sites were in bold, numbered and with orientation indicated by horizontal arrows. A pair of inversely oriented IntI-binding domains, S1 and S2, constituted the putative simple site, while DR1 and DR2 represented core site-like direct repeats. The vertical arrow indicated the known recombination crossover point for insertion of the first gene cassette. The sequence region derived from the first gene cassette was in lower case. Numbers between brackets represented the identical copies of the corresponding attI sequence.

the associated direct repeats seen in attI1, an arrangement analogous to that seen for attI3 and in some previously identified attI sequences from an environmental DNA (Nield et al., 2001; Collis et al., 2002). Only, three clones, Suez4, Suez14 and Tokyo17, contained putative direct repeat sites, with almost typical sequences, GTTACGC of DR1, for Suez4 and attI1; and GTTATA(G)G of DR2, for Suez14 and attI1 (Figure 4). The absence of direct repeat sequences in most recovered attI sites may affect the recombination activity of these sites or suggest that the associated IntI proteins do not rely on them in the same way that IntI1 does (Partridge et al., 2000). However, it has been suggested that these direct repeats act as enhancers by retaining the
IntI1 recombinase in the vicinity of the simple site (Gravel et al., 1998).

First recovery of both gene cassette promoter, $P_{c}$, and the first gene cassettes associated with marine integrons

Application of current PCR amplification methodology using the primers intI-864R and GCP2 achieved two outcomes in terms of integron-associated gene cassette recovery. These were the recovery and identification of the first gene cassette linked to an integron at attI and the recovery of the region that normally includes the promoter, $P_{\mathrm{c}}$, responsible for gene cassette expression. Each of these recovered integron regions were examined for a possible 
Table 3 Current integron gene cassette sequence orientations

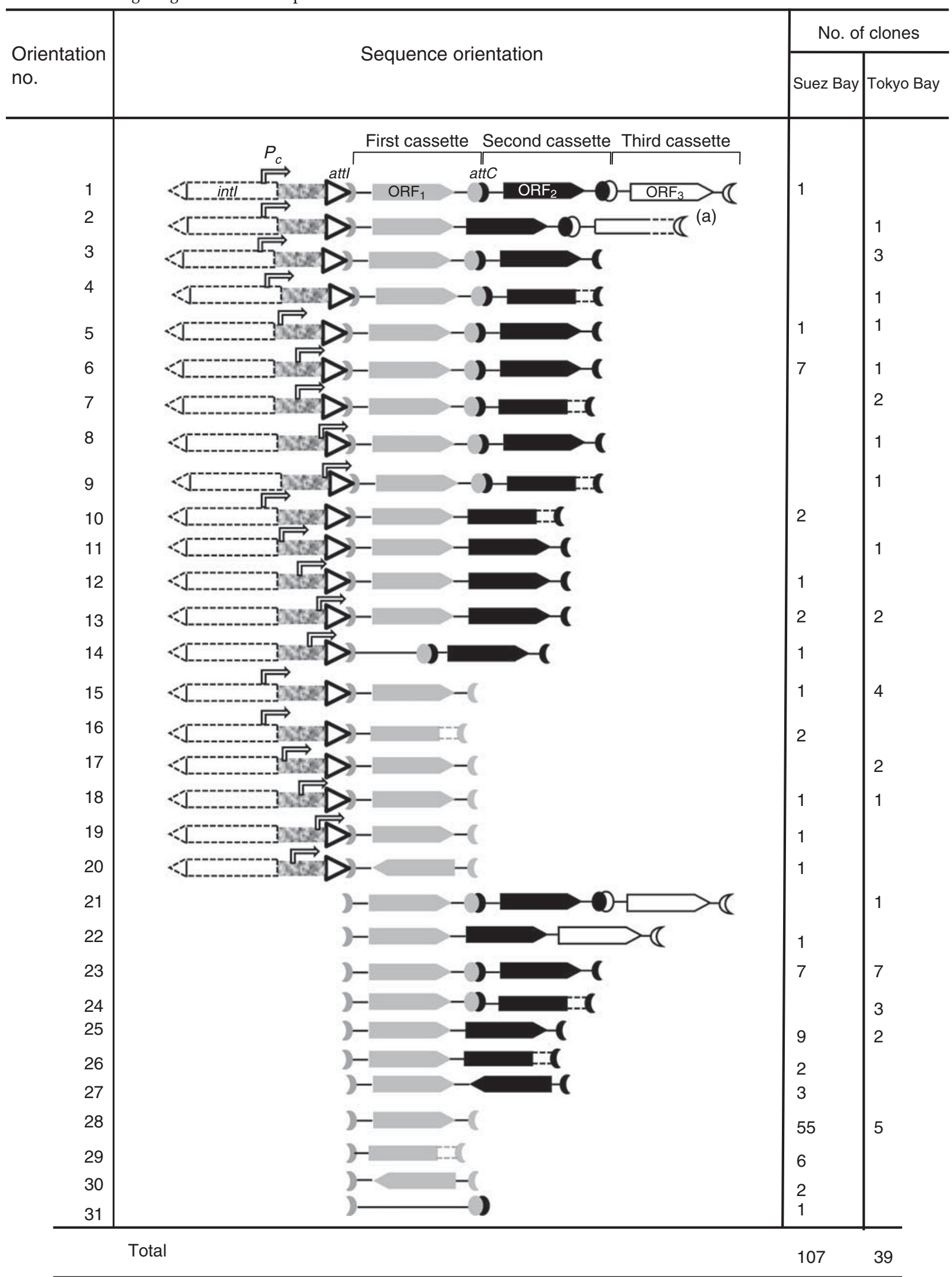

(a) A gene cassette with an incomplete ORF 
Table 4 Diversity of gene cassettes within the samples

\begin{tabular}{lcc}
\hline Gene cassette diversity & Suez & Tokyo \\
\hline Total number of cassettes & $146(37+109)^{\mathrm{a}}$ & $68(36+32)^{\mathrm{a}}$ \\
Observed richness (cassettes & $100(21+79)$ & $63(32+31)$ \\
types) & $290.82(133.86)$ & $491.27(370.58)$ \\
Chao 1 richness estimator & $3.68(0.16)$ & $3.39(0.23)$ \\
Shannon-Weiner index & & \\
\hline
\end{tabular}

${ }^{\mathrm{a} N u m b e r}$ of gene cassettes amplified by primer set intl-864R/ GCP2+those of amplified by the primer set GCP1/GCP2.

$P_{\mathrm{c}}$ promoter. In all cases, prokaryotic-like promoter sequences with close fit to the consensus TTGACA(17 bp)TATAAT were identified and their relative positions were indicated in Table 3 . Most of the integrons found here contained putative $P_{\mathrm{c}}$ promoter sequences, with -35 and -10 regions, having at least three nucleotides of each of the sixbase pairs matching to the consensus with typical spacing, a feature similar to that in class 1 integrons (Kim et al., 2007), and a match and spacing likely to allow biological levels of transcription (Zhou and Yang, 2006). Some current $P_{\mathrm{c}}$ promoters had sequences with high similarity to the promoter consensus sequences such as a promoter TTGAGA (17 bp)TAATAG, clone Suez6. Such single-nucleotide polymorphisms may control the strength of $P_{\mathrm{c}}$ promoter and consequently, the level of gene cassette expression (Kim et al., 2007). However, the current $P_{\mathrm{c}}$ promoter sequences and those identified previously in environmental integrons (Nield et al., 2001) have been predicted using software and an experimental evidence is needed to confirm the activity of theses promoters. This study could recover up to three integrated gene cassettes in some cases, including the full structure of the first gene cassette, which was found to vary from 250 to $1254 \mathrm{bp}$.

How big and diverse are the pools of gene cassettes in Suez and Tokyo Bays?

In addition to the intI-864R/GCP2 long PCR that recovered one or more cassettes linked with intI genes, another PCR approach, using the primer set GCP1/GCP2, was used, in parallel, for recovering a diverse range of gene cassettes from the two sample sites. Using both PCR approaches, a total of 146 and 68 gene cassettes were recovered and grouped into 100 and 63 cassette types, respectively, representing Suez and Tokyo Bay clone libraries, respectively (Tables 3 and 4). It was concluded, from the Chao 1 richness estimator value, that the total richness of the cassette pool of Tokyo Bay sample was higher than that of Suez (Table 4). This was consistent with rarefaction curves, which implied a trend to more diversity over the same number of sampled cassettes (Figure 5) and with Shannon-Weiner diversity index values (Table 4). Further sampling would be needed to determine if this is a transient

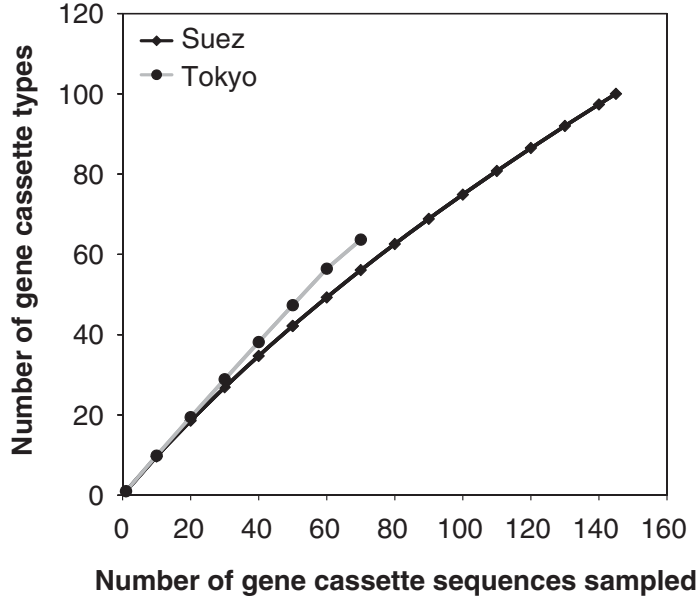

Figure 5 Rarefaction curves showed the richness of gene cassettes at the maximum sample sizes, 146 and 68 gene cassettes, for Suez and Tokyo Bay samples, respectively.

phenomenon or one that is stable over time. If the latter, other mobile cassette molecular and ecological analyses would have interest to establish any causal link between these observations.

A total of 17 families of attC were detected from current gene cassette surveys (Supplementary Figure 2). Some of the first gene cassettes had complete ORFs but lacked an attC site and were followed by a second gene cassette, forming orientation numbers 10, 11, 12 and 13 (Table 3). Usually, lacking of attC prevents gene cassettes from being recognized by the integrase enzyme. If these gene cassettes are essential for survival, this may select for the loss of these recombination sites to prevent gene excision. On the other hand, a first gene cassette, SuezGC14.1, was recorded as an empty gene cassette, consisting of only an attC without ORF (Table 3, orientation no. 14), an implication of a nonfunctional gene cassette.

Some attC sequences from both current sampling sites showed highly similarities and belonged to the same attC family (Supplementary Figure 2). Also, six Tokyo Bay gene cassette attC sequences, with a same size of $69 \mathrm{bp}$, showed an average nucleotide identity value of $73.0 \%$ with that from a deep-sea hydrothermal vent gene cassette (Elsaied et al., 2007), an observation confirming the existence of conserved attC structures in completely different marine habitats.

The gene cassettes encoded proteins with adaptive functions

Of the total 146 and 68 analyzed gene cassettes, 143 and 68 gene cassettes were found to encode predicted proteins from Suez and Tokyo Bay gene cassette pools, respectively. These gene cassettes had predicted ORFs with typical expression orientations (Table 3) as in Stokes et al. (2001) and Elsaied et al. (2007). That is, the gene was oriented such that expression of $P_{\mathrm{c}}$ is possible. We could identify gene 


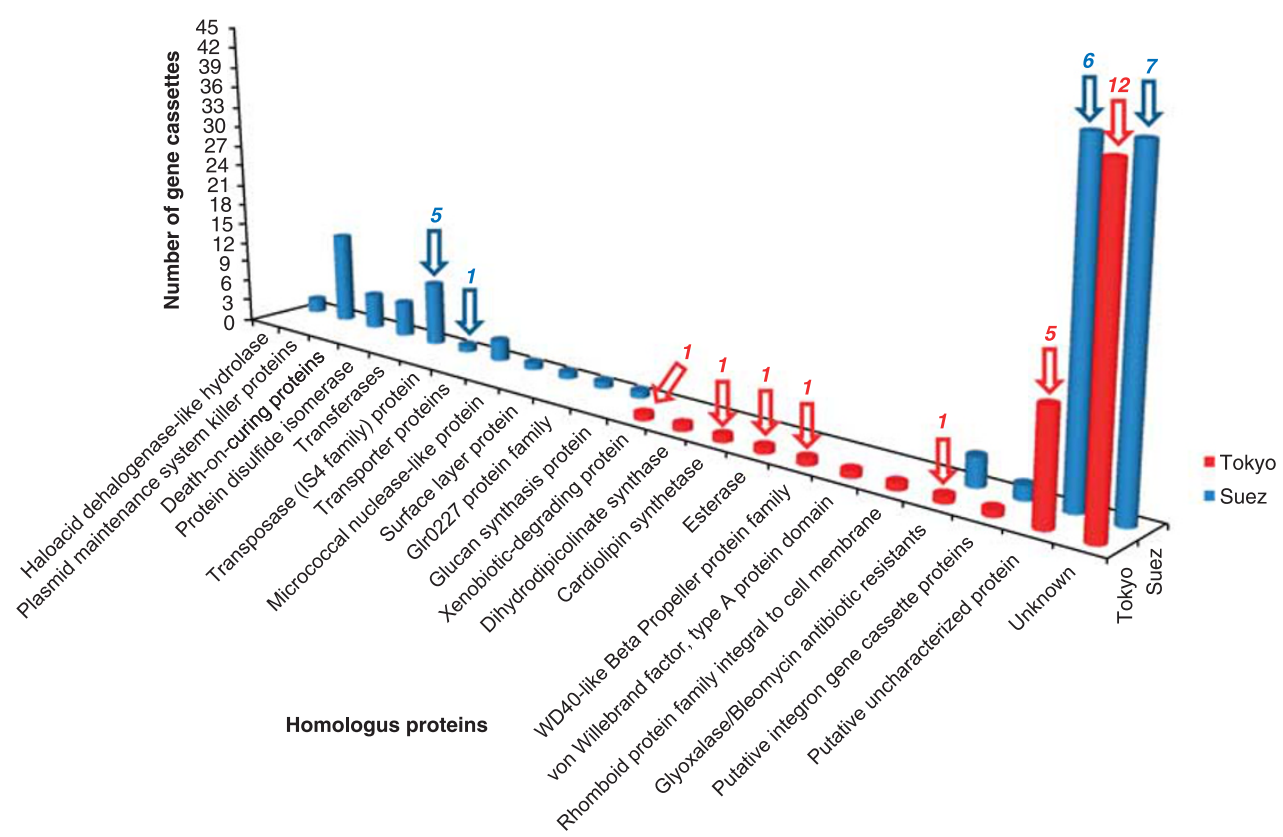

Figure 6 Histogram showed protein coding capacities of gene cassettes recovered from both sampling sites. The down arrows and the labels above the arrows showed the protein coding bars contained first gene cassette proteins and their numbers in each bar, respectively.

cassettes, which encoded proteins with environment adaptive functions (Figure 6). The example for environment adaptive genes, which occurred in both sampling sites, was represented by gene cassettes SuezGC32.1, SuezGC74.1, SuezGC88.1, SuezGC96.1 and the first gene cassette TokyoGC14.1, which encoded proteins with significant homology (e-value $<0.001$ ) with glyoxalase/bleomycin antibioticresistance proteins from Vibrio parahaemolyticus and Bacillus weihenstephanensis, respectively. The antibiotic bleomycin was first produced by actinomycetes, as an antitumor agent used in clinical settings, and against which there are known resistance genes (Suzuki et al., 1969; Shen et al., 2002). This is the first occurrence of bleomycin resistance genes in marine sediments and it was theoretically expected as both Suez and Tokyo Bay sampling sites are suffering from varieties of anthropogenic pollution. To survive in these niches, each bacterium must develop a resistance to myriad natural antibiotics (D'Costa et al., 2006). Bleomycin resistance genes have been spread to nonclinical environmental bacteria such as those living in activated sludge (Mori et al., 2008). The deduced amino acid identities between bleomycin resistance genes recorded in Suez Bay and that of in Tokyo Bay were low, with an average of $23.0 \%$, representing two different unique families of this gene and supporting the occurrence of these gene variants in nonclinical environments (Mori et al., 2008).

Each sampling site has specific characteristics, implying specific and different niche adaptations. One demonstration of this was in the occurrence of two gene cassettes, SuezGC59.1 and SuezGC93.1, which encoded haloacid dehalogenase-like hydrolases (Figure 6), recording an amino acid identity average of $43.0 \%$ with that of Marinomonas sp. This enzyme specifically acts on halide bonds in carbonhalide compounds and participates in degradation of both $\gamma$-hexachlorocyclohexane and 1,2-dichloroethane, a toxic long-lived organochlorine, which has been detected in the current sampling site of Suez Bay (El-Agroudy et al., 2006). Moreover, occurrence of gene cassettes that encoded haloacid dehalogenases may be correlated with the stress of high concentration of polycyclic aromatic hydrocarbons in Suez sediment (Domínguez-Cuevas et al., 2006; Nemr et al., 2006) (Supplementary Table 1). The detection of five Suez gene cassette-encoded proteins homologous to disulfide isomerase (Figure 6), an enzyme associated with oil sand pollution, supported the role of gene cassette pool as a source for varieties of pollution signal-related genes (Crowe et al., 2001; Koenig et al., 2009). Generally, expression studies on these gene cassettes would be beneficial to assay for the relevant enzyme activities and, consequently, support the current results. However, this study focused on the functional diversity of gene cassettes in coding varieties of adaptive deduced proteins specific for sampling site characteristics.

The Suez gene cassette pool was found to harbor two genomic systems, plasmid maintenance system killer and death-on-curing, which are involved in stabilizing extra-chromosomal DNA (Paul et al., 2005). The plasmid system killer genome was 
represented by a total of six clones, each of which carried two gene cassettes, one encoded stable killer protein followed by another gene cassette encoded unstable inhibitor protein, antidote, and gave homology average of $70.0 \%$, with those located in multidrug resistance operons of Gamma- and Deltaproteobacterial species (DeNap and Hergenrother, 2005). One of the five gene cassettes, SuezGC32.2, encoded death-on-curing proteins, was flanked upstream by the gene cassette, SuezGC32.1, which encoded bleomycin antibiotic-resistance protein. It was unclear whether there was a functional relationship between these two adjacent cassettes. However, both the two types of the predicted proteins, bleomycin resistance and death-on-curing, are considered general responses to environmental stresses. The first gene cassette SuezGC15.1 encoded DNAbinding transposase, IS4 protein family, an evidence for a transposon source. Gene cassettes encoded transposases have been recorded in a deep-sea environment, an implication for the role of transposon, as a transfer element, in the mobility and evolution of marine integrons and associated gene cassettes (Elsaied et al., 2007).

The gene cassette TokyoGC20.1 encoded a predicted xenobiotic-degrading protein. Xenobiotics are very often found in the context of the presence of industrial wastes such as dioxins and polychlorinated biphenyls, which commonly occur in Tokyo Bay sediments (Naito and Murata, 2007; Zushi et al., 2010). The location of TokyoGC16.1 as a first gene cassette may facilitate its high expression of the encoded esterase, as responses to toxic metals and antibiotics (Stepanauskas et al., 2005; Brandt et al., 2009). This implication may be supported by the significant homology of the current gene cassetteencoded esterase with that of Shewanella sediminis, a marine sediment bacterium that has the ability to degrade several toxic industrial chemical wastes and generates much interest in the field of bioremediation (Zhao et al., 2005). Another first gene cassette, TokyoGC6.1, was found to encode cardiolipin synthetase, an enzyme having stress sensitivity to several drugs and some chemical solvents like toluene (Bernal et al., 2007). The first gene cassette TokyoGC11.1 encoded a unique family of the WD40like Beta Propeller protein, which is involved in a variety of cell functions such as environment signal transductions (Hudson and Cooley, 2008). Other gene cassettes from both sites encoded a nuclease and a protease rhomboid protein family, key enzymes for digestion of nucleic acids and membrane proteins, respectively, and having a role in the term of biotechnology (Figure 6).

\section{Dominance of first gene cassettes that encoded} unknown proteins but predicted signal functions

The current gene cassette pools were dominated by gene cassettes that had no significant homology in databases (Figure 6), a common feature of gene cassettes from environmental metagenomes. Of the total of 42 clones analyzed from both site clone libraries, 11 and 19 first gene cassettes encoded both putative uncharacterized proteins, homologous with those from several bacterial sources, and proteins with no homologs, unknown, respectively (Table 5). Although these gene cassettes included proteins with no identifiable functions, the insertion orientation was such that the corresponding gene had the potential to be expressed from $P_{\mathrm{c}}$. In the clones Tokyo12 and Tokyo19, a cassette was duplicated, presenting at both the first and second positions. Such a circumstance potentially and actually leads to higher levels of expression of the gene in question compared with the cassette being present only once (Collis and Hall, 1995). The deduced protein encoded by this duplicated gene cassette was predicted as being an unstable protein with a signal functional site, a feature characterizing several unknown gene cassette proteins listed in Table 5 . Most of these gene cassette proteins had theoretical isoelectric points $\mathrm{pI}>7$. If the $\mathrm{pH}$ of the bacterial surrounding medium is 7 , the common medium $\mathrm{pH}$, these protein terminals would have positive charges, which are essential for transfer of signals as an initial step of protein secretion across the membrane (Inouye et al., 1982; Vergunst et al., 2005). These proteins would clearly be interesting targets for further functional characterization.

\section{Biogeographic expansion of gene cassette pool in marine sediments}

Two gene cassettes from Suez Bay, SuezGC9.2 and SuezGC38.2 and the Tokyo Bay gene cassette, TokyoGC29.1 showed significant homologies with those recovered from marine sediments in Halifax Harbour, Canada (Koenig et al., 2008). Both Suez and Tokyo Bays, like Halifax Harbour, are urban marine habitats suffering from varieties of anthropogenic pollutions; some of them may be common in the three geographic distant sites. The common occurred pollutant in distant habitats may shape a similar gene cassette structure that can be used as a mobile DNA marker specific for that pollutant. On the other hand, occurrence of glyoxalase/bleomycin resistance gene cassettes in both sites suggested the variable expanding of these gene cassettes in marine sediments. The anthropogenic pollution may accelerate the transfer of these genes from clinical field into natural marine environment. The wide occurrence of gene cassettes that encoded transferase-like enzymes in marine surface sediment from Suez Bay (Figure 6), Halifax Harbour (Koenig et al., 2008), estuaries (Wright et al., 2008) and deep-sea hydrothermal vents (Elsaied et al., 2007) probably suggests the global marine biogeographic distribution of these gene cassette proteins. On the other hand, there was a significant similarity between the gene cassette SuezGC98.2 protein and a methyltransferase from the archaeon Methanosaeta thermophila, 
1174

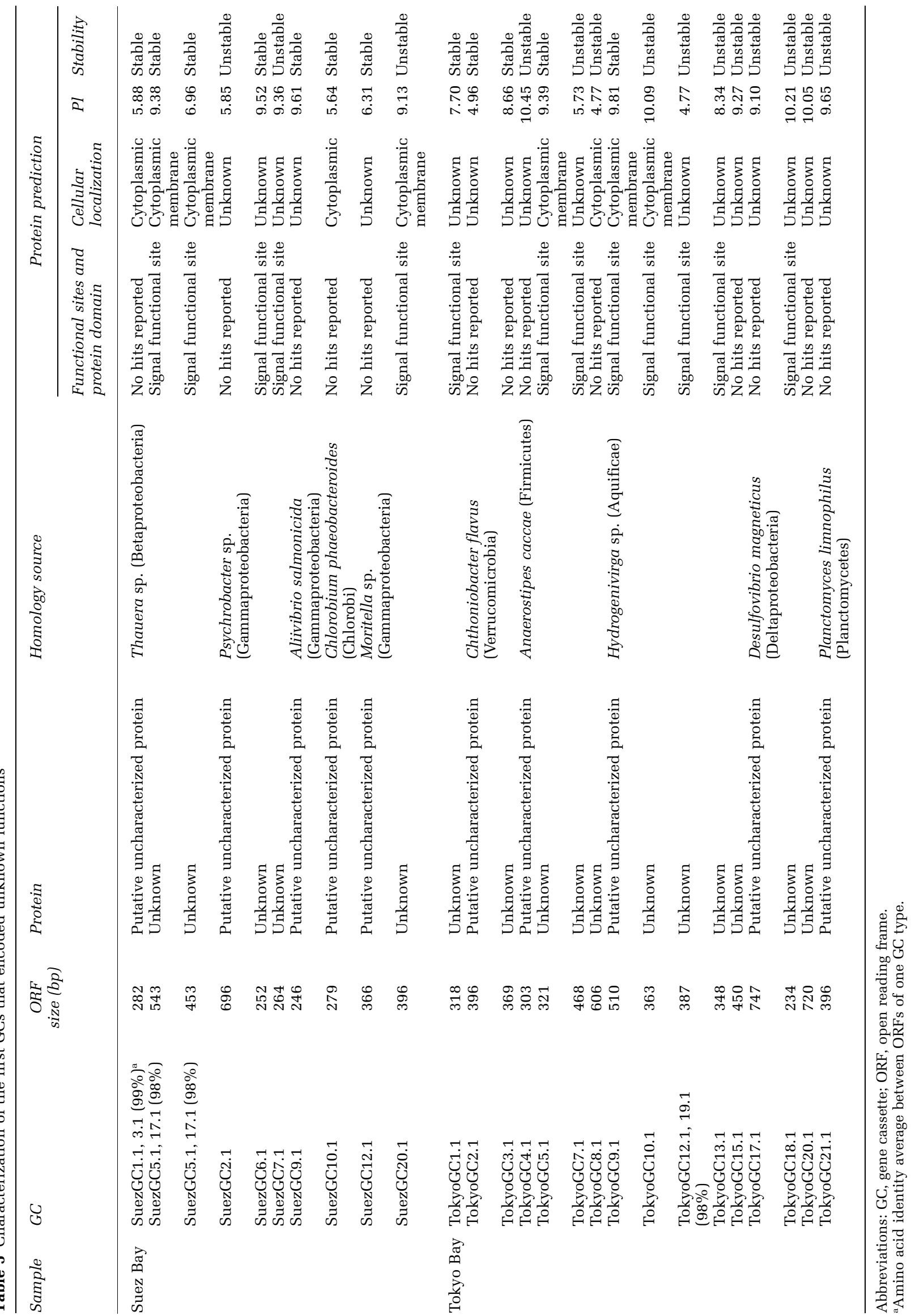


implying an example of lateral gene transfer between bacteria and archaea. These observations may conclude that the biogeographically distribution of gene cassettes in marine environments is affected by several factors, some of which are natural and others are anthropogenic.

This work could improve studying the composition and function of marine integron/gene cassette metagenome. Our current approach is still focusing on addressing several difficulties in studying the marine integrons and associated gene cassettes through improvement of the monitoring and uncovering the ecological role of that metagenome in a wide range of marine environments. In addition, the novelty of the recovered gene cassettes is likely to provide a source of proteins for commercial applications.

\section{Acknowledgements}

We are grateful to National Institute of Advanced Industrial Science and Technology, AIST, Japan, and National Institute of Oceanography, Egypt, for offering facilities for marine sediment sampling. We thank Dr Hiroyuki Fuse and the technician Ms Aya Akiba for helping and providing facilities for experiments. The present study has been supported by the Grantin-Aid for Scientific Research, KAKENHI (no. 19201041) from Japan Society for the Promotion of Science (JSPS), as well as a basic fund from the National Institute of Advanced Industrial Science and Technology, AIST, Japan.

\section{References}

Bernal P, Muñoz-Rojas J, Hurtado A, Ramos J, Segura A. (2007). A Pseudomonas putida cardiolipin synthesis mutant exhibits increased sensitivity to drugs related to transport functionality. Environ Microbiol 9: $1135-1145$.

Berthe-Corti L, Nachtkamp M. (2010). Bacterial communities in-hydrocarbon-contaminated marine coastal environments. In: Timmis KN (ed). Handbook of Hydrocarbon and Lipid Microbiology. Springer-Verlag, Berlin, Heidelberg, pp 2350-2357.

Boucher Y, Labbate M, Koenig JE, Stokes HW. (2007). The integron: an adaptable and mobilizable platform that promotes genetic diversity in bacteria. Trends Microbiol 15: 301-309.

Brandt K, Sjøholm O, Krogh K, Halling-Sørensen B, Nybroe O. (2009). Increased pollution-induced bacterial community tolerance to sulfadiazine in soil hotspots amended with artificial root exudates. Environ Sci Technol 43: 2963-2968.

Chao A. (1984). Non-parametric estimation of the number of classes in a population. Scand J Stat 11: 265-270.

Collis CM, Hall RM. (1995). Expression of antibiotic resistance genes in the integrated cassettes of integrons. Antimicrob Agents Chemother 39: 155-162.

Collis CM, Kim MJ, Stokes HW, Hall RM. (2002). Integron encoded IntI integrases preferentially recognize the adjacent cognate attI site in recombination with a 59-be site. Mol Microbiol 46: 1415-1427.
Crowe A, Han B, Kermode A, Bendell-Young L, Plant A. (2001). Effects of oil sands effluent on cattail and clover: photosynthesis and the level of stress proteins. Environ Pollut 113: 311-322.

D'Costa VM, McGrann KM, Hughes DW, Wright GD. (2006). Sampling the antibiotic resistome. Science 311: 374-377.

DeNap JC, Hergenrother PJ. (2005). Bacterial death comes full circle: targeting plasmid replication in drug-resistant bacteria. Org Biomol Chem 3: 959-966.

Domínguez-Cuevas P, González-Pastor J, Marqués S, Ramos J, de Lorenzo V. (2006). Transcriptional tradeoff between metabolic and stress-response programs in Pseudomonas putida KT2440 cells exposed to toluene. J Biol Chem 281: 11981-11991.

El-Agroudy N, El Azim H, Soliman Y, Said T, El Moselhy K. (2006). Concentrations of petroleum hydrocarbons in water and some marine organisms of the Gulf of Suez. Egyptian J Aquatic Res 32: 128-143.

Elsaied H, Maruyama A. (2010). Diversity and role of bacterial integron/gene cassette metagenome in extreme marine environments. In: de Bruijn FJ (ed). Handbook of Molecular Microbial Ecology II: Metagenomics in Different Habitats. Wiley-Blackwell, Weinheim, Germany.

Elsaied H, Stokes HW, Nakamura T, Kitamura K, Fuse H, Maruyama A. (2007). Novel and diverse integron integrase genes and integron-like gene cassettes are prevalent in deep-sea hydrothermal vents. Environ Microbiol 9: 2298-2312.

Goto M, Kato M, Asaumi M, Shirai K, Venkateswaran K. (1994). TLC/FID method for evaluation of the crudeoil-degrading capability of marine microorganisms. J Mar Biotechnol 2: 45-50.

Gravel A, Fournier B, Roy PH. (1998). DNA complexes obtained with the integron integrase IntI1 at the attI1 site. Nucleic Acids Res 26: 4347-4355.

Hall RM, Collis CM, Kim MJ, Partridge SR, Recchia GD, Stokes HW. (1999). Mobile gene cassettes and integrons in evolution. Ann N Y Acad Sci 870: 68-80.

Hartmann M, Widmer F. (2006). Community structure analyses are more sensitive to differences in soil bacterial communities than anonymous diversity indices. Appl Environ Microbiol 72: 7804-7812.

Holmes AJ, Gillings MR, Nield BS, Mabbutt BC, Nevalainen KM, Stokes HW. (2003). The gene cassette metagenome is a basic resource for bacterial genome evolution. Environ Microbiol 5: 383-394.

Horii Y, Ohura T, Yamashita N, Kannan K. (2009). Chlorinated polycyclic aromatic hydrocarbons in sediments from industrial areas in Japan and the United States. Arch Environ Contam Toxicol 57: 651-660.

Huang L, Cagnon C, Caumette P, Duran R. (2009). First gene cassettes of integrons as targets in finding adaptive genes in metagenomes. App Environ Microbiol 75: 3823-3825.

Hudson AM, Cooley L. (2008). Phylogenetic, structural and functional relationships between WD- and Kelchrepeat proteins. Subcell Biochem 48: 6-19.

Inouye S, Soberontf X, Franceschini T, Nakamura K, Itakurat K, Inouye M. (1982). Role of positive charge on the amino-terminal region of the signal peptide in protein secretion across the membrane. Proc Natl Acad Sci USA 79: 3438-3441.

Kim TE, Kwon HJ, Cho SH, Kim S, Lee BK, Yoo HS et al. (2007). Molecular differentiation of common 
promoters in Salmonella class 1 integrons. J Microbiol Methods 68: 453-457.

Koenig JE, Boucher Y, Charlebois RL, Nesbø C, Zhaxybayeva O, Bapteste E et al. (2008). Integronassociated gene cassettes in Halifax Harbour, assessment of a mobile gene pool in marine sediments. Environ Microbiol 10: 1024-1038.

Koenig JE, Sharp C, Dlutek M, Curtis B, Joss M, Boucher Y et al. (2009). Integron gene cassettes and degradation of compounds associated with industrial waste: the case of the Sydney Tar Ponds. PLOS ONE 4: e5276.

Labbate M, Case RJ, Stokes HW. (2009). The integron/gene cassette system: an active player in bacterial adaptation. Methods Mol Biol 532: 103-125.

Lane D, Pace B, Olsen G, Stahl D, Sogin M, Pace N. (1985). Rapid determination of $16 \mathrm{~S}$ ribosomal sequences for phylogenetic analyses. Proc Natl Acad Sci USA 82: 6955-6959.

Liu Y, Harrison PM, Kunin V, Gerstein M. (2004). Comprehensive analysis of pseudogenes in prokaryotes: widespread gene decay and failure of putative horizontally transferred genes. Genome Biol 5: R64.

MacDonald D, Demarre G, Bouvier M, Mazel D, Gopaul DN. (2006). Structural basis for broad DNA-specificity in integron recombination. Nature 440: 1157-1162.

Mazel D. (2006). Integrons: agents of bacterial evolution. Nat Rev Microbiol 4: 608-620.

Messier N, Roy PH. (2001). Integron integrases possess a unique additional domain necessary for activity. J Bacteriol 183: 6699-6706.

Mori T, Mizuta S, Suenaga H, Miyazaki K. (2008). Metagenomic screening for bleomycin resistance genes. Appl Environ Microbiol 74: 6803-6805.

Naito W, Murata M. (2007). Evaluation of population-level ecological risks of dioxin-like polychlorinated biphenyl exposure to fish-eating birds in Tokyo Bay and its vicinity. Integr Environ Assess Manag 3: 68-78.

Nemergut DR, Martin AP, Schmidt SK. (2004). Integron diversity in heavy-metal-contaminated mine tailings and inferences about integron evolution. Appl Environ Microbiol 70: 1160-1168.

Nemergut DR, Robeson M, Kysela R, Martin A, Schmidt S, Knight R. (2008). Insights and inferences about integron evolution from genomic data. BMC Genomics 9: 261.

Nemr AE, Khaled A, El-Sikaily A, Said TO, Abd-Allah AM. (2006). Distribution and sources of polycyclic aromatic hydrocarbons in surface sediments of the Suez Gulf. Environ Monit Assess; E-pub ahead of print 13 June 2006, doi: 10.1007/s10661-005-9009-4.

Nield BS, Holmes AJ, Gillings MR, Recchia GD, Mabbutt BC, Nevalainen KM et al. (2001). Recovery of new integron classes from environmental DNA. FEMS Microbiol Lett 195: 59-65.

Nunes-Duby SE, Kwon HJ, Tirumalai RS, Ellenberger T, Landy A. (1998). Similarities and differences among 105 members of the Int family of site-specific recombinases. Nucleic Acids Res 26: 391-406.

Partridge SR, Recchia GD, Scaramuzzi C, Collis CM, Stokes HW, Hall RM. (2000). Definition of the attI1 site of class 1 integrons. Microbiology 146: 2855-2864.

Partridge SR, Tsafnat G, Coiera E, Iredell JR. (2009). Gene cassettes and cassette arrays in mobile resistance integrons. FEMS Microbiol Rev 33: 757-784.

Paul D, Pandey G, Jain RK. (2005). Suicidal genetically engineered microorganisms for bioremediation: need and perspectives. BioEssays 27: 563-573.
Robinson A, Guilfoyle A, Harrop S, Boucher Y, Stokes HW, Curmi $P$ et al. (2007). A putative house-cleaning enzyme encoded within an integron array: $1.8 \AA$ crystal structure defines a new MazG subtype. Mol Microbiol 66: 610-621.

Rodríguez-Minguela CM, Apajalahti JH, Chai B, Cole JR, Tiedje JM. (2009). Worldwide prevalence of class 2 integrases outside the clinical setting is associated with human impact. Appl Environ Microbiol 75: 5100-5110.

Schloss PD, Westcott SL, Ryabin T, Hall JR, Hartmann M, Hollister EB et al. (2009). Introducing Mothur: opensource, platform-independent, community-supported software for describing and comparing microbial communities. Appl Envir Microbiol 75: 7537-7541.

Shannon CE, Weaver W. (1963). The Mathematical Theory of Communication. University of Illinois Press: Urbana, IL.

Shen B, Du LC, Sanchez C, Edwards DJ, Chen M, Murrell JM. (2002). Cloning and characterization of the bleomycin biosynthetic gene cluster from Streptomyces verticillus ATCC15003. J Nat Prod 65: 422-431.

Simberloff D. (1978). Use of rarefaction and related methods. In: Dickson KL et al (eds). Biological Data in Water Pollution Assessment Quantitative and Statistical Analyses. American Society for Testing and Materials: Philadelphia, pp 150-165.

Singleton D, Furlong M, Rathbun S, Whitman W. (2001). Quantitative comparisons of $16 \mathrm{~S}$ rRNA gene sequence libraries from environmental samples. Appl Environ Microbiol 67: 4374-4376.

Stepanauskas R, Glenn T, Jagoe C, Carytuckfield R, Lindell A, Mcarthur J. (2005). Elevated microbial tolerance to metals and antibiotics in metal-contaminated industrial environments. Environ Sci Technol 39: 3671-3678.

Stokes HW, Hall R. (1989). A novel family of potentially mobile DNA elements encoding site-specific geneintegration functions: integrons. Mol Microbiol 3: 1669-1683.

Stokes HW, Holmes AJ, Nield BS, Holley MP, Nevalainen KM, Mabbutt BC et al. (2001). Gene cassette PCR: sequence-independent recovery of entire genes from environmental DNA. Appl Environ Microbiol 67: 5240-5246.

Stokes HW, O’Gorman DB, Recchia GD, Parsekhian M, Hall RM. (1997). Structure and function of 59-base element recombination sites associated with mobile gene cassettes. Mol Microbiol 26: 731-745.

Suzuki H, Nagai K, Yamaki H, Tanaka N, Umezawa H. (1969). On the mechanism of action of bleomycin: scission of DNA strands in vitro and in vivo. J Antibiot 22: $446-448$.

Uchimiya M, Arai M, Masunaga S. (2007). Fingerprinting localized dioxin contamination: Ichihara Anchorage case. Environ Sci Technol 41: 3864-3870.

Vergunst AC, van Lier MC, Dulk-Ras A, Stuve TA, Ouwehand A, Hooykaas PJ. (2005). Positive charge is an important feature of the C-terminal transport signal of the VirB_D4-translocated proteins of Agrobacterium. Proc Natl Acad Sci USA 102: 832-837.

Wright MS, Baker-Austin C, Lindell AH, Stepanauskas R, Stokes HW, McArthur JV. (2008). Influence of industrial contamination on mobile genetic elements: class 1 integron abundance and gene cassette structure in aquatic bacterial communities. ISME $J \mathbf{2}$ : 417-428. 
Zhao J, Manno D, Beaulieu C, Paquet L, Hawari J. (2005). Shewanella sediminis sp. nov., a novel Na+-requiring and hexahydro-1,3,5-trinitro-1,3,5- triazine-degrading bacterium from marine sediment. Inter J Syst Evol Microbiol 55: 1511-1520.

Zhou D, Yang R. (2006). Global analysis of gene transcription regulation in prokaryotes. Cell Mol Life Sci 63: 2260-2290.

Zushi Y, Tamada M, Kanai Y, Masunaga S. (2010). Time trends of perfluorinated compounds from the sediment core of Tokyo Bay, Japan (1950s-2004). Environ Pollut

Supplementary Information accompanies the paper on The ISME Journal website (http://www.nature.com/ismej) 